\title{
Gasification of biofuels blended from olive mill solid wastes and pine sawdust under different carbon dioxide/nitrogen atmospheres
}

\author{
M. Zribi ${ }^{\mathrm{a}}$, M. Lajili ${ }^{\mathrm{a}, *}$, F.J. Escudero-Sanz ${ }^{\mathrm{b}}$ \\ ${ }^{a}$ UR: EMIR (Étude des Milieux Ionisés et Réactifs), IPEIM, Monastir 5019, Tunisia \\ ${ }^{\mathrm{b}}$ RAPSODEE: Centre de recherche d'Albi en génie des procédés des solides divisés, de l'énergie et de l'environnement, École des mines d'Albi Carmaux, Campus Jarlard \\ 81013 Albi CT Cédex 09, France
}

\author{
Keywords: \\ Biochar \\ $\mathrm{CO}_{2}$ gasifier \\ Conversion \\ Rate of conversion \\ Char reactivity
}

\begin{abstract}
A B S T R A C T
In this paper, we investigated the gasification of charcoals using a macro TG under $\mathrm{CO}_{2}$ mixed with nitrogen at different percentages $\left(40 \%, 70 \%\right.$ and $\left.100 \% \mathrm{CO}_{2}\right)$ and at different fixed temperatures $\left(750{ }^{\circ} \mathrm{C}, 800{ }^{\circ} \mathrm{C}\right.$, and $\left.900{ }^{\circ} \mathrm{C}\right)$. For this purpose, two raw residues were selected; the exhausted olive mill solid wastes (EOMSW) and the pine sawdust (PS). Then, four different samples, which have not been previously studied with a gasification process, were prepared from these residues when investigating the impregnated and the non-impregnated ones using the olive mill waste water (OMWW) as by-product for the impregnation process. Moreover, a comparison between results obtained during this study and those obtained during a previous study based on steam gasification was carried out. It was found that the mass loss profiles are consistent with the usual lignocellulosic gasification behaviors. Also, the increase of temperatures or $\mathrm{CO}_{2}$ percentages affects positively the conversion, the gasification rate and the char reactivity. It is worth noting that $\mathrm{CO}_{2}$ acts differently from steam. With steam, gasification is found to be faster and more reactive.
\end{abstract}

\section{Introduction}

Fossil fuel combustion has contributed greatly to the unprecedented levels of pollution affecting the environment. These effects on the environment have resulted in renewed interest in renewable energy sources. In this context, biomass and more specifically biofuels have emerged as a sustainable source to meet energy demand thanks to its high availability and low cost. Indeed, biomass presently contributes $10-15 \%$ of the global energy demand, which places it in third place after coal and oil [1-3]. The sources of biomass, of course, vary from one region to region and between countries. For Tunisia, the olive mill solid wastes (OMSW) and the olive mill wastewater (OMWW) provided by olive oil manufactures are the most available biomass resources averaging about 400,000 tons of OMSW and about 1,200,000 tons of OMWW per year. For France, major contributors to biomass include forest residues [4] (oaks, pines, holm oaks and cork oaks) and agricultural residues [5] (cereal residues, vegetables wastes and fruit wastes). It should be remembered that on the basis of 1 ton of OMSW, up to $10 \%$ of residual oil can be extracted for the manufacture of any kind of soap (liquid/solid). The rest (approximately $900 \mathrm{~kg}$ per metric ton) of solid residue can provide furfural (10\%) after proper chemical treatment using hydrolysis with sulphuric acid $0.1 \mathrm{M}$, and extraction using $\mathrm{CCl}_{4}$. The rest which is about $800 \mathrm{~kg}$ per ton can be used as solid fuel [6]. Currently, Tunisia exports exhausted olive mill solid wastes (EOMSW) to European countries (mainly Italy and Spain), which are used as fuel for industrial furnaces. These data justify our choice on OMSW and on pine sawdust (PS) in order to carry out the present study. The annual world OMWW production varies from 7 to over 30 million $\mathrm{m}^{3}$ [7]. The volume of OMWW produced during the 3-phase process (olive black water) is $0.5-0.8 \mathrm{~m}^{3} /$ ton of olive [8]. This by-product is a complex pollutant mixture causing serious ecological problems when stored in huge quantities in natural basins without any treatment. Indeed, the OMWW is characterized by its chemical oxygen demand (COD) and its biological oxygen demand (BOD) reaching high concentrations of 100 and $220 \mathrm{~kg} \cdot \mathrm{m}^{-3}$, respectively. Moreover, the OMWW, which consists of organic and inorganic compounds, is characterized by its high acidity $[9,10]$. The main organic compounds of this type of biomass are lignin, tannin, phenolics, long-chain fatty acid responsible of phytotoxic and antibacterial activities. The principal inorganic compounds are potassium, calcium, sodium, magnesium etc. $[7,10-12]$. However, several researches have confirmed that OMWW can be impregnated on dry biomasses to produce green fuels with improved quality [13], for agricultural irrigation or as soil fertilizers when used in small quantities, and as fuel since it holds a great energetic

\footnotetext{
* Corresponding author.

E-mail addresses: marzouk.lajili@ipeim.rnu.tn (M. Lajili), javier.escuderosanz@mines-albi.fr (F.J. Escudero-Sanz).
} 
potential (up to $18 \mathrm{MJ} / \mathrm{kg}$, dry basis) [11]. This work shows the importance of the impregnation procedure using the OMWW by-product due to its richness in organic/inorganic matter. Note that biomass can be valorized energetically by three routes: physicochemical, biochemical and thermochemical [14] routes. The thermochemical route includes pyrolysis $[15,16]$, combustion $[17,18]$, gasification $[19,20]$ etc. In the present study, two different processes were investigated: an isothermic pyrolysis for producing charcoal in a horizontal furnace, and then a gasification of the prepared charcoal in a Macro-TG. Our choice is based on the flexibility of such process with different types of biomass that can be converted into Syngas generating all kinds of secondary energy [21]. It is a relatively new process well known as a new environmentally friendly process needing relatively high temperatures of up to $1400{ }^{\circ} \mathrm{C}$ [22-24]. Biomass gasification involves gasifiers such as the supply of air, steam or carbon dioxide mixed with an inert gas like nitrogen or argon [25,26]. However, the use of $\mathrm{CO}_{2}$ in gasification appears as a promising strategy that can also reduce $\mathrm{CO}_{2}$ emissions. In this scenario, $\mathrm{CO}_{2}$ reacts in the gas phase with hydrogen molecules according to the reverse water gas shift reaction [27]:

$\mathrm{CO}_{2}+\mathrm{H}_{2} \rightarrow \mathrm{H}_{2} \mathrm{O}+\mathrm{CO} \quad \Delta \mathrm{H}=+41.2 \mathrm{~kJ} / \mathrm{mol}$

$\mathrm{CO}_{2}$ can also react with hydrocarbons such as methane via the dry reforming reaction:

$\mathrm{CO}_{2}+\mathrm{CH}_{4} \rightarrow 2 \mathrm{H}_{2}+2 \mathrm{CO} \quad \Delta \mathrm{H}=+246.9 \mathrm{~kJ} / \mathrm{mol}$

Moreover, $\mathrm{CO}_{2}$ can react with the carbon contained in the char prepared by the pyrolysis process according to the heterogeneous Boudouard reaction:

$\mathrm{C}+\mathrm{CO}_{2} \rightarrow 2 \mathrm{CO} \quad \Delta H=-179.5 \mathrm{~kJ} / \mathrm{mol}$

$\mathrm{C}+2 \mathrm{H}_{2} \leftrightarrow \mathrm{CH}_{4} \quad \Delta H=-75 \mathrm{~kJ} / \mathrm{mol}$

Furthermore, the pyrogasification is a complex process involving three main steps: pyrolysis, volatile-matter reforming and char gasification. The char gasification reaction is considered as the limiting step of the process because it is slower compared to the other steps [28].

Which motivates us is the fact that we value an abundant biomass in Tunisia (EOMSW) and another abundant biomass in France and in Europe (PS) using an innovative process (the gasification). Moreover, the chars' reactivity's and the competitiveness between two gasifiers $\left(\mathrm{CO}_{2}\right.$ and $\left.\mathrm{H}_{2} \mathrm{O}\right)$ at different concentrations and temperatures were investigated. This could solve the problem of lack of energy for Tunisia and the problem of pollution caused by the OMWW. Besides, this policy reduces the effect of overexploitation of forests and wood by-products in Europe. Moreover, a key feature of this study was the fact that these samples were rarely studied by thermochemical processes, but perhaps never by gasification under $\mathrm{CO}_{2}$. Hence, after preliminary preparation of the char in the horizontal furnace, we conducted fast gasification tests under an atmosphere of a mixture of $\mathrm{N}_{2}$ and $\mathrm{CO}_{2}$. We focused on the effect of the $\mathrm{CO}_{2}$ percentages and temperatures on the conversion and its rate and the char reactivity. Moreover, a comparison between these tests and those realized in a previous study [29] allows identifying which gasifier is more efficient.

\section{Material and methods}

\subsection{Samples preparation}

The olive mill solid wastes (EOMSW) used in this work were obtained from the olive oil and soap factory of Zouila, Tunisia, while, the pine sawdust (PS) was provided by a wood factory situated in France. Samples were prepared using the same procedure detailed in our previous study $[12,29]$. Four samples types were prepared from the densified residues with and without impregnation with the olive mill wastewater (OMWW):
- PS: composed of $100 \%$ pine sawdust.

- PS-OMWW: impregnated PS by OMWW.

- EOMSW-OMWW: Impregnated EOMSW by OMWW.

- EOMSW: composed of $100 \%$ olive mill solid waste.

The PS-OMWW and EOMSW-OMWW were prepared when adding $100 \mathrm{~kg}$ of OMWW with $89 \%$ of moisture (in wet basis) to $20 \mathrm{~kg}$ of PS and $20 \mathrm{~kg}$ of EOMSW in a ratio (5:1) for each sample respectively (for more details see [12]). During the impregnation phase, it is impossible to use more of OMWW (overcome the ratio 5:1) because of the limitation of adsorption.

After pyrolysis, the obtained chars were crushed and sieved resulting in a powder with particle sizes less than $100 \mu \mathrm{m}$.

\subsection{Methods}

To prevent the negative impact on the reactivity during gasification between volatiles and chars, it is recommended to carry out an atypical gasification strategy separating pyrolysis and gasification into two separate steps $[30,31]$. In a first step, slow pyrolysis was carried out under an inert atmosphere using a horizontal furnace in order to produce the recommended chars used during the gasification step. In a second step, the samples were crushed and sieved. The obtained product is a powder of less than $100 \mu \mathrm{m}$ size. Then, themogravimetric analyses were carried out using a Macro-TG reactor as illustrated in Fig. 1 (see ref. to [32] for a more detailed discussion). The plate on which the samples must be placed has a surface of $16 \pi 10^{-4} \mathrm{~m}^{2}$ (about $8 \mathrm{~cm}$ diameter). The average speed of the fluid entering the reactor cannot exceed $0.2 \mathrm{~m} / \mathrm{s}$ to ensure that the flow remains laminar. The volume flow of nitrogen was $610^{-3}$ $\mathrm{Nm}^{3} / \mathrm{min}$. At every experimental run, when the sample is placed in the middle of the electric furnace, we monitor the mass loss using Electronic scales with $1 \mu \mathrm{g}$ precision (Sartorius Analytical Balance MSU524S-100-DI).

However, when heating the platinum basket, on which the samples are placed, and the ceramic tubes in which circulates the gas flow, the flowing gas dynamic pressure (whichh combines the force exerted on the basket and the drag forces along the ceramic tubes) yields the mass change up to thermal equilibrium. Once such thermal equilibrium was reached and the gas flow was stabilized around the basket and the ceramic tubes, the displayed mass will remain constant. In order to overcome this problem, a preliminary blank test is needed. Then, by simple elimination between blank and real tests, the real mass loss can be determined and corrected for. In this study, we define some key parameters characterizing the gasification process:

The char's reactivity was obtained following the expression:

$\mathrm{R}=\frac{\frac{\mathrm{dX}}{\mathrm{dt}}}{1-\mathrm{X}_{\mathrm{t}}}$

Where $\mathrm{X}$ is the conversion of char during the gasification, which is defined as:

$\mathrm{X}=\frac{\mathrm{m}_{0}-\mathrm{m}_{\mathrm{t}}}{\mathrm{m}_{0}-\mathrm{m}_{\mathrm{ash}}}$

In this expression, $\mathrm{m}_{0}, \mathrm{~m}_{\mathrm{t}}$ and $\mathrm{m}_{\mathrm{ash}}$ are the initial mass of char, the mass at instant $\mathrm{t}$ and the mass of the residual ash, respectively. Moreover, when following the Hognon et al. [33] demarche, it is possible to determine an intrinsic and constant kinetic parameter $\mathrm{k}$. Indeed, the kinetic law governing the gasification can be simply written as:

$\frac{\mathrm{dX}}{\mathrm{dt}}=\mathrm{k}\left(\mathrm{P}_{\mathrm{CO} 2}, \mathrm{~T}\right) \mathrm{F}(\mathrm{x})$

where $\mathrm{k}$ is the intrinsic kinetic parameter, $\mathrm{P}_{\mathrm{CO} 2}$ is the carbon dioxide partial pressure, and $\mathrm{F}(\mathrm{x})$ is a structural function describing the change in active sites concentration. This function can be obtained from experimental results at any conversion level following the equation: 
M: Mass flowmeter/controller

T: Thermocouple

(1) Evaporator

(2) Preheater

(3) Ceramic tube

(4) Electric furnace

(5) Platinium basket and biomass sample

(6) Crank handle

(7) Electronic scale

(8) Cyclone

(9) Data acquisition

(10) Extractor
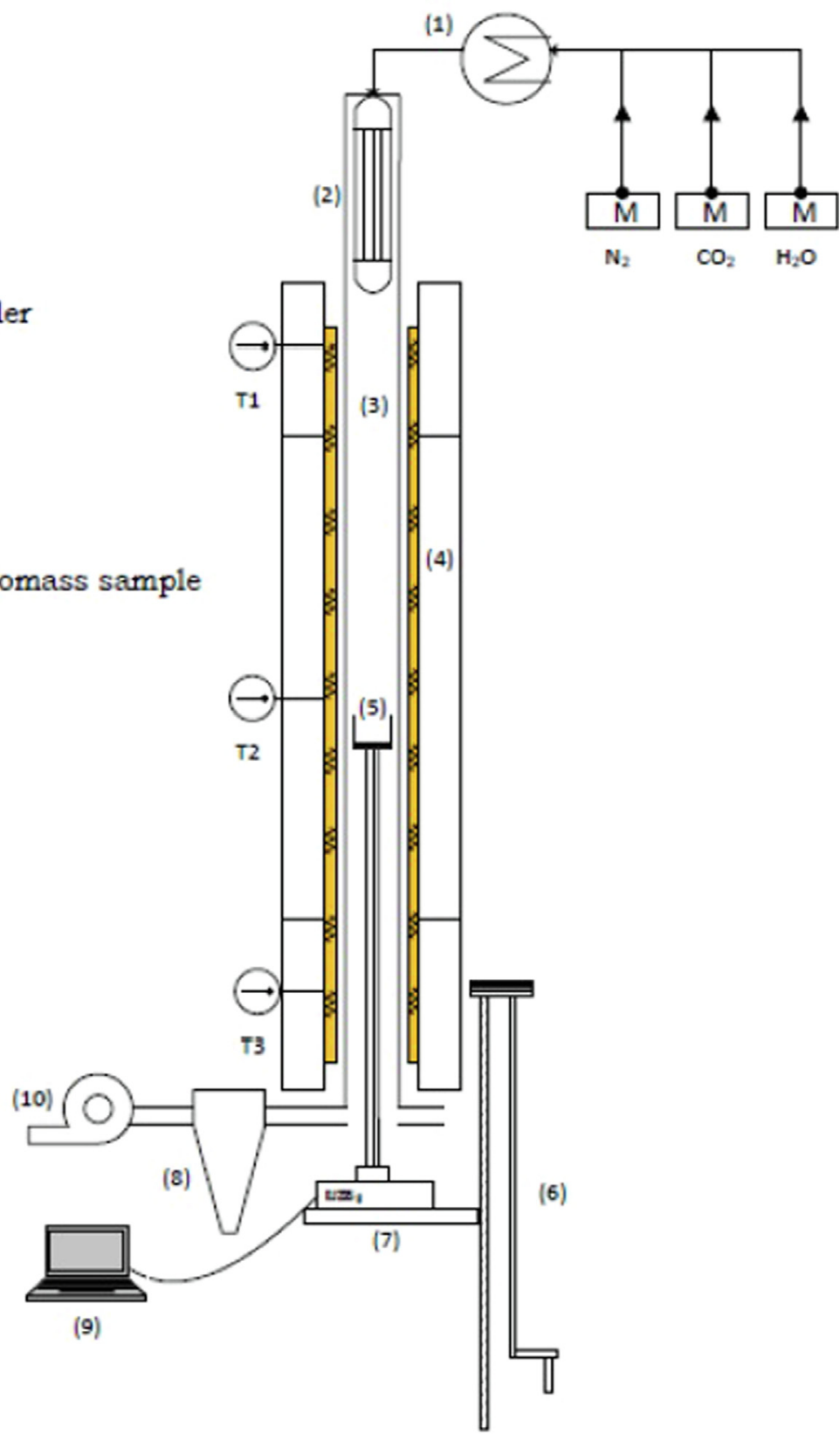

Fig. 1. Sketch of the Macro-TG device.

$F(X)=\frac{R(X)}{R(\text { ref })}$

Note that the partial pressure of a component of a gas mixture is the product of the molar fraction of this component and the total pressure of the mixture (Raoult's law):

$P_{i}=x_{i} P$

In our study, the rate of conversion, the reactivity and the structural function are determined for a conversion between 0.2 and 0.8 when the reference reactivity was fixed at $\mathrm{X}=0.5[28,34,35]$. This range was chosen to minimize uncertainties for the small mass loss in the early stages of the reaction ( $\mathrm{X} \in[0,0.2]$ ), and to avoid high reactivity values in the final stages of the reaction $(X \in[0.8,1.0])$ [28].

Correlations expressing $\mathrm{k}$ as a function of temperature and partial pressure were reported in the literature [25]. Moreover, a common expression for $\mathrm{k}$ is the following:
$k=A \exp \left(\frac{-E_{a}}{R T}\right) P_{C O 2}^{b}$

where $\mathrm{A}$ is the pre-exponential factor, $\mathrm{E}_{\mathrm{a}}$ is the activation energy, $\mathrm{R}$ is the universal gas constant and $\mathrm{b}$ is an exponent highlighting the influence of the $\mathrm{CO}_{2}$ partial pressure. The latter parameters can be determined only experimentally. For this study, and because of the absence of alternative models for the gasification of these samples types in the literature, we chose to start with a simple model [36]:

$\frac{d X}{d t}=k\left(P_{C O 2}, T\right)(1-X)$

By integration of Eq.11, the conversion $\times$ takes the following expression:

$X=1-\exp \left(-k_{1} t\right)$

where, $\mathrm{k}_{1}$ is a kinetic constant which could be determined by least squares regression method (Table 1). 
Table 1

Kinetic constant values during PSOMWW gasification at $750{ }^{\circ} \mathrm{C}$.

\begin{tabular}{ll}
\hline $\mathrm{CO} 2 \%$ & $\mathrm{~s}^{-1}$ unit \\
\hline $100 \% \mathrm{CO}_{2}$ & $\mathrm{k}_{1}=0,0069$ \\
$70 \% \mathrm{CO}_{2}$ & $\mathrm{k}_{2}=0,0051$ \\
$40 \% \mathrm{CO}_{2}$ & $\mathrm{k}_{3}=0,0033$ \\
\hline
\end{tabular}

\section{Results and discussions}

In this section, we discuss the effects of the temperature and the $\mathrm{CO}_{2}$ partial pressure on the char gasification process for the samples under investigation. A comparison between the effect of the carbon dioxide and the steam will be also carried out. To study the reactivity profiles, we performed experiments in which we varied the temperature at constant gas partial pressure and vice versa. The Labview system's acquisition allows us to record the mass loss of char during gasification. By using Eq. (6), it is possible to calculate the conversion $\mathrm{X}$ at each elapsed time step.

\subsection{CO2 gasification experiments}

3.1.1. Effects of the $\mathrm{CO}_{2}$ percentage on the Conversion, the rate of conversion and the char reactivity

Fig. 2 shows the influence of the variation of the $\mathrm{CO}_{2}$ percentage on the conversion. In agreement with $[28,37,38]$, it is obvious that when the $\mathrm{CO}_{2}$ percentage is increased from 40 to $100 \%$, the char conversion gradually increases and simultaneously the required time of the char gasification gradually decreases.

At a reference temperature of $750{ }^{\circ} \mathrm{C}$, a conversion level of $90 \%$ was reached after 350, 500 and $700 \mathrm{~s}$ in gasifying atmospheres containing $100 \%, 70 \%$ and $40 \%$ of $\mathrm{CO}_{2}$, respectively. Therefore, increasing of the $\mathrm{CO}_{2}$ from $40 \%$ to $100 \%$ results in a doubling of the higher char reactivity. Similar behaviors were found at 800 and $900{ }^{\circ} \mathrm{C}$.

Experimental and modelled conversions were compared versus time as shown on Fig. 2. It is seen that model and experiment exhibit the same trend [33]. However, we do not observe a perfect agreement between results of the experiment and of the model. This may be attributed to the fact that the chosen model is not very suitable to the studied sample type. This result will provide some guidance to improve the model by considering the samples' inorganic composition (mainly

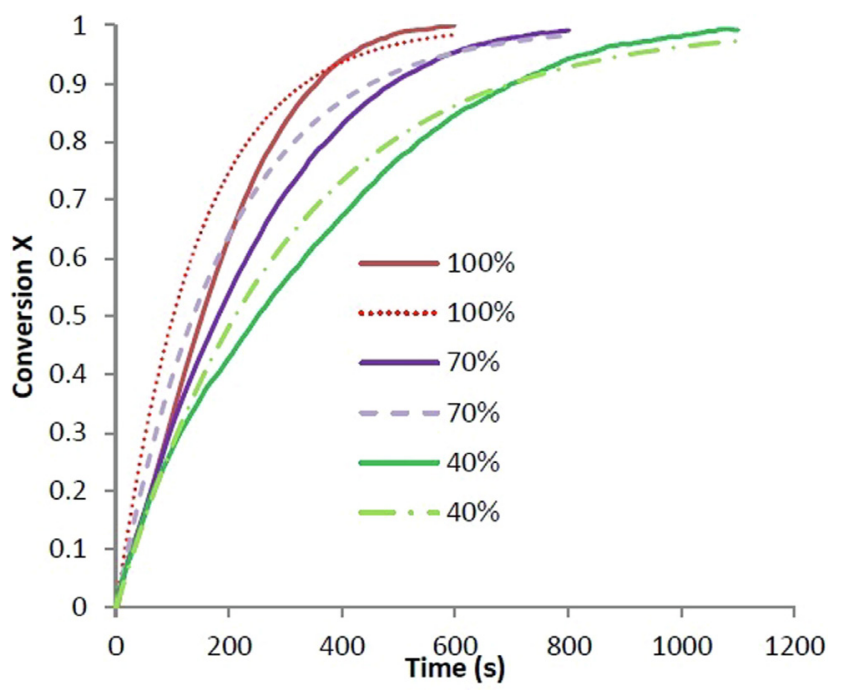

Fig. 2. Influence of the $\mathrm{CO}_{2}$ percentage on the conversion of impregnated PS by OMWW at $750{ }^{\circ} \mathrm{C}$. Solid and dashed lines correspond to experiment and model (Eq. (12)) respectively.

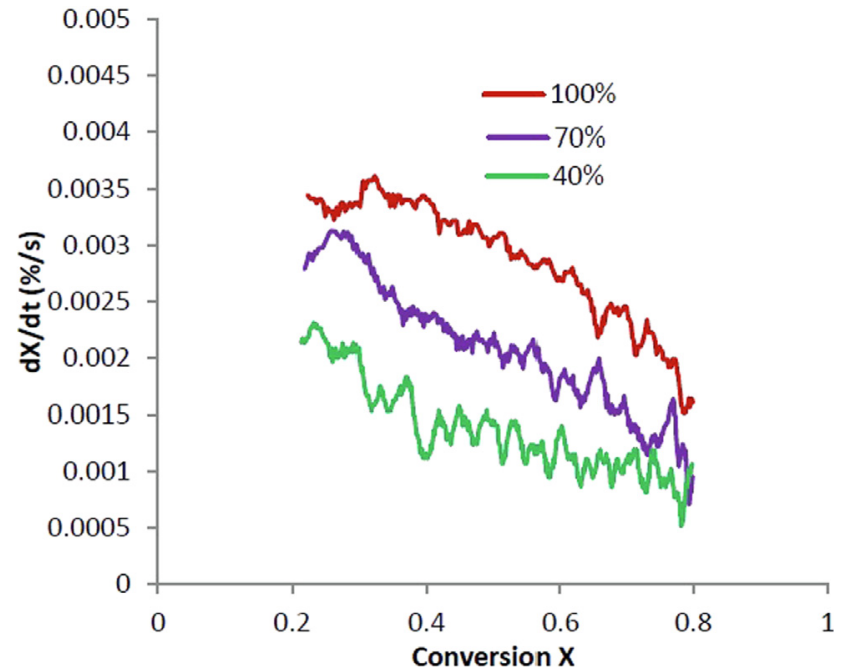

Fig. 3. Influence of $\mathrm{CO}_{2}$ percentage on the rate of conversion at $750{ }^{\circ} \mathrm{C}$ for impregnated PS by OMWW.

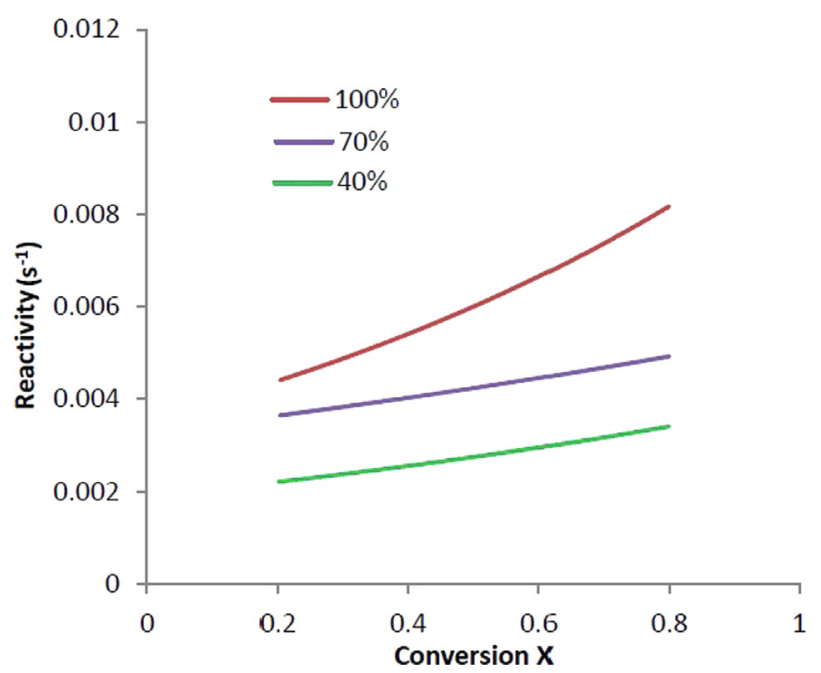

Fig. 4. Influence of $\mathrm{CO} 2$ percentage on the char gasification reactivity at $750{ }^{\circ} \mathrm{C}$ for impregnated PS by OMWW.

$\mathrm{K}, \mathrm{Si}, \mathrm{P}$ ) because of their crucial role in the kinetics of gasification due to their catalytic effects.

Figs. 3 and 4 illustrate the influence of the $\mathrm{CO}_{2}$ on the rate of conversion and the char reactivity at $750{ }^{\circ} \mathrm{C}$ for PS-OMWW, respectively. It can be clearly seen that the char reactivity increases as the $\mathrm{CO}_{2}$ percentage is increased from 40 to $100 \%$. This result was expected since with a higher $\mathrm{CO}_{2}$ concentration, the probability of reaction on available active sites on the char surface area increases. Furthermore, this result shows that there is no $\mathrm{CO}_{2}$ percentage effect limitation as it was stated by Guizani et al. [28] for whom $30 \% \mathrm{CO}_{2}$ is the limit for maximum reactivity. This is may be attributed to the specificity of samples used in this study (mainly organic and inorganic composition) per rapport to wood chips used by Guizani et al. [28].

3.1.2. Effects of the temperature on the Conversion, the rate of conversion and the char reactivity

The effect of the temperature on the conversion is evaluated using experiments realized with temperature ranging between 750 and $900{ }^{\circ} \mathrm{C}$. Fig. 5 shows the char conversion evolution versus elapsed time when testing EOMSW for a percentage of $100 \% \mathrm{CO}_{2}$ and for three different temperatures. The results show an increase in the char conversion and, consequently, a decrease of the characteristic time of 


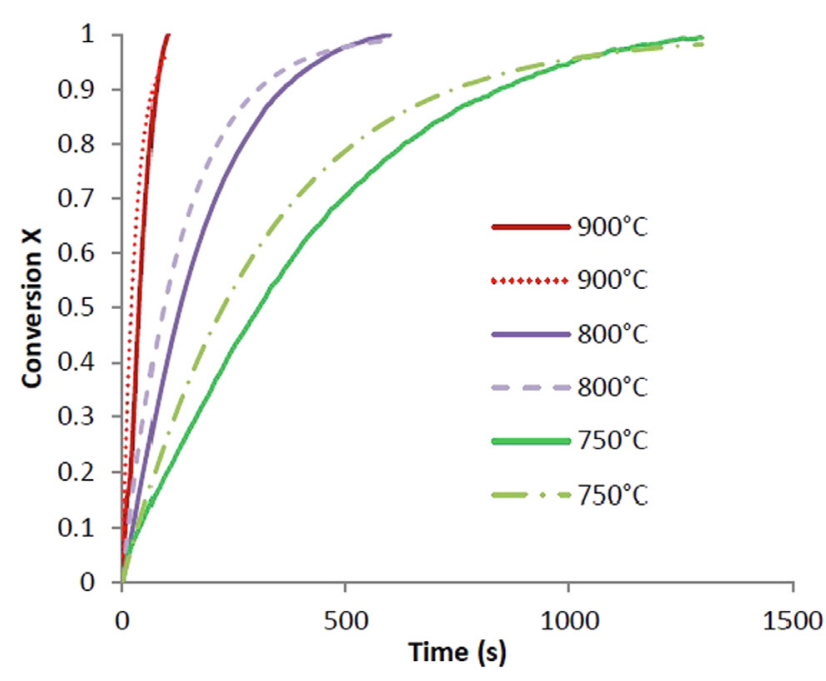

Fig. 5. Influence of temperature on the conversion of EOMSW under $100 \% \mathrm{CO}_{2}$. Solid and dashed lines correspond to experiment and model (Eq. (12)) respectively.

gasification. This conclusion is consistent with some results reported in the literature [39-41]. Indeed, Tong et al. [39] realized lignite char gasification tests using $\mathrm{CO}_{2}, \mathrm{H}_{2} \mathrm{O}$ and their mixture in a fluidized bed reactor. They observed that the reactivity of gasification enhances rapidly when the temperature increases from $1333^{\circ} \mathrm{C}$ to $1483{ }^{\circ} \mathrm{C}$. As for Mani et al. [40], they noticed that at a rate of conversion equal to $50 \%$ during biomass char gasification with $\mathrm{CO}_{2}$ the reactivity increases with temperature, and it decreases as the particle size increases. In addition, Hodge et al. [41] concluded that conversion during coal chars gasification with $\mathrm{CO}_{2}$ increases with increasing residence time and reaction wall temperature. In the present study and conformingly to Fig. 5, the complete conversion was reached after $100,500,1080 \mathrm{~s}$ with temperatures of $900,800,750{ }^{\circ} \mathrm{C}$, respectively. Accordingly, a $150{ }^{\circ} \mathrm{C}$ increase in the gasification temperature ten-fold increase in reactivity [35].

The kinetic constant $\mathrm{k}$ is also determined for the EOMSW using least squares regression (Table 2) to compare the experimental and modelled conversions in Fig. 5. Moreover, except $900{ }^{\circ} \mathrm{C}$ curve profile for which the model and experimental curves are in a good agreement, the two other profiles show discrepancies. This allows to the conclusion that the model we used is not very suitable for these types of samples and for certain range of temperature.

Besides, for a given percentage of $\mathrm{CO}_{2}$, the effect of the variation of the temperature from 750 to $900{ }^{\circ} \mathrm{C}$ on the rate of conversion and the char's reactivity is shown in Fig. 6, and Fig. 7. One can conclude that the samples become more reactive when temperature is increased $[28,35]$. Indeed, the influence of temperature can be explained by the fact that gasification process is governed by several endothermic reactions (such as Eqs. (3) and (4) [42]. For example, the carbon hydrogenation resulting in methane formation is enhanced by temperature and the optimum conditions correspond to $\mathrm{T}$ above $1100{ }^{\circ} \mathrm{C}$ and pressures between 0.6 and $0.8 \mathrm{MPa}$ when using nickel as catalyst [43].

Table 2

Kinetic constant values during EOMSW gasification under $100 \% \mathrm{CO}_{2}$.

\begin{tabular}{ll}
\hline Temperature & $\mathrm{s}^{-1}$ unit \\
\hline $900{ }^{\circ} \mathrm{C}$ & $\mathrm{k}_{1}=0,034$ \\
$800{ }^{\circ} \mathrm{C}$ & $\mathrm{k}_{2}=0,0076$ \\
$750{ }^{\circ} \mathrm{C}$ & $\mathrm{k}_{3}=0,0031$
\end{tabular}

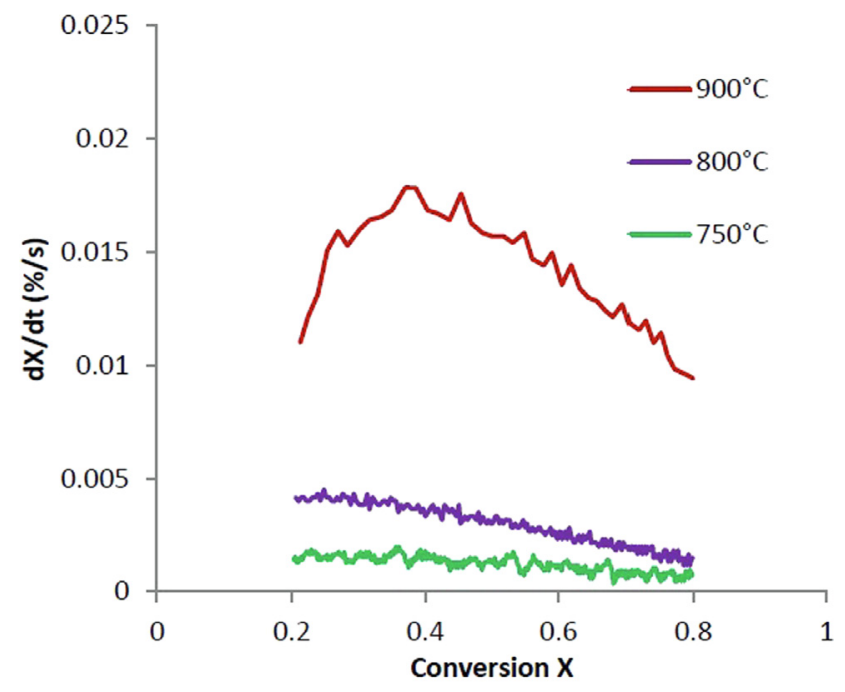

Fig. 6. Influence of temperature on the rate of conversion of EOMSW under $100 \% \mathrm{CO}_{2}$.

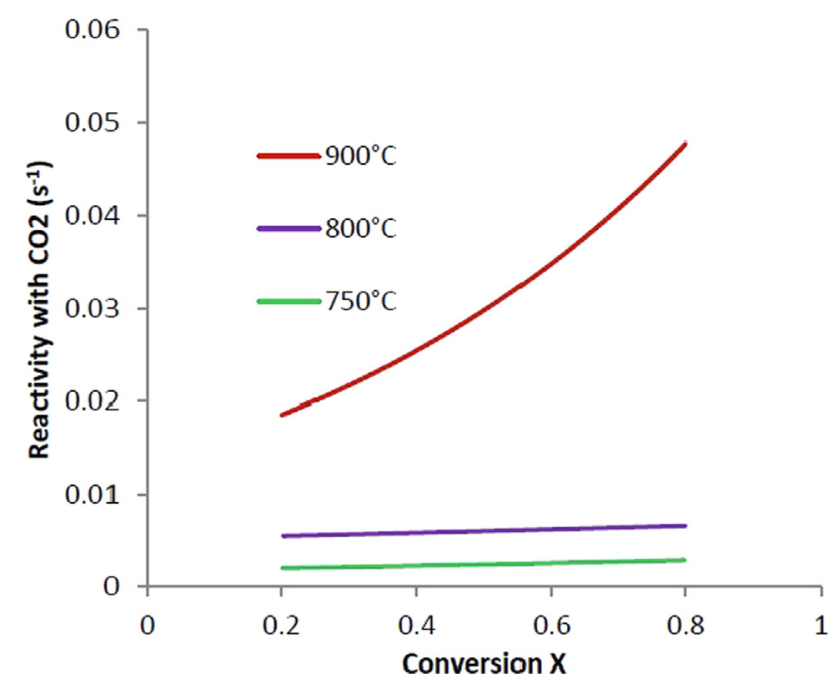

Fig. 7. Influence of temperature on the char gasification reactivity of EOMSW under $100 \% \mathrm{CO}_{2}$.

3.1.3. Effects of the impregnation by OMWW on the Conversion, the rate of conversion and the char reactivity

The OMWW used for the impregnation process and the production of (EOMSW-OMWW) sample is characterized by organic and inorganic compounds. Table 3 shows that alkali metals such as potassium, calcium and sodium are highly concentrated in the impregnated samples compared to the raw ones. Moreover, it was reported in the literature that these inorganic elements exhibit catalytic effects during gasification $[44,45]$.

Fig. 8 shows clearly the effect of the OMWW on the char gasification at $800{ }^{\circ} \mathrm{C}$ and for $70 \% \mathrm{CO}_{2}$. Indeed, of the impregnation process by OMWW enhances the char reactivity and reduces the characteristic

Table 3

Concentration of the main inorganic elements in the used samples $(\mathrm{g} / \mathrm{kg}$ dry basis).

\begin{tabular}{lllll}
\hline Parameter & EOMSW & EOMSW-OMWW & PS & PS-OMWW \\
\hline $\mathrm{K}$ & 3.67 & 7.53 & 0.36 & 3.40 \\
$\mathrm{Ca}$ & 1.13 & 1.45 & 0.36 & 0.87 \\
$\mathrm{Na}$ & 0.78 & 1.79 & 0.01 & 1.15 \\
\hline
\end{tabular}




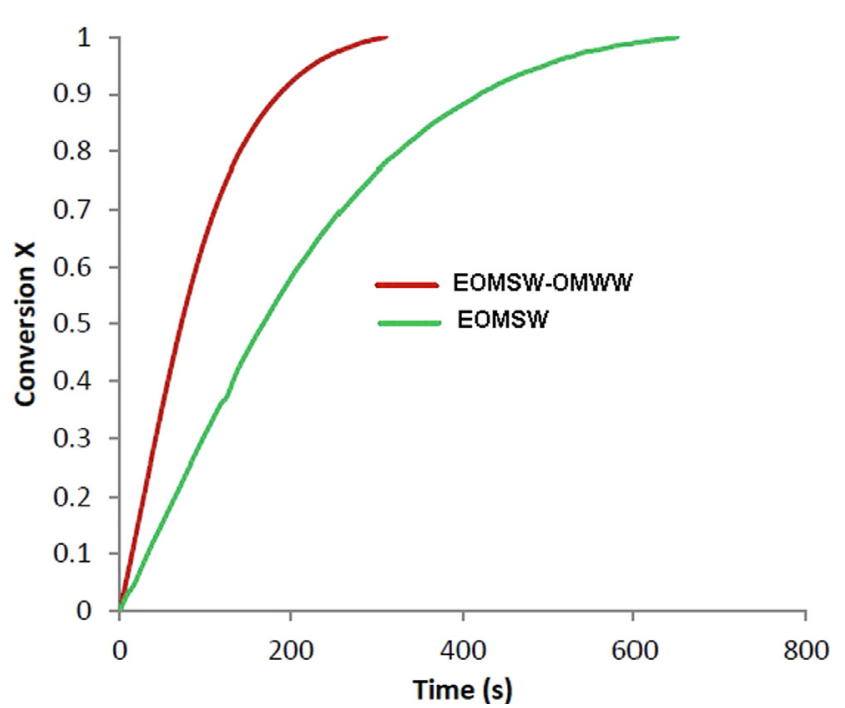

Fig. 8. Influence of the impregnation process on the EOMSW conversion under $70 \% \mathrm{CO}_{2}$ and at $800{ }^{\circ} \mathrm{C}$.

time for a $90 \%$ of conversion by more than a factor of 3 .

Also, as can be seen in Figs. 9 and 10 for a temperature of $800{ }^{\circ} \mathrm{C}$ and for $70 \% \mathrm{CO}_{2}$, the rate of conversion $\mathrm{dX} / \mathrm{dt}$, which is as an indicator of the samples' reactivity, depends strongly on the samples' type. Hence, the addition of the OMWW for each sample enhances its reactivity thanks to its richness in inorganic matter (K, Ca and $\mathrm{Na})[6,46]$.

\section{2. $\mathrm{H}_{2} \mathrm{O}$ vs $\mathrm{CO}_{2}$ gasification experiments:}

3.2.1. Comparison between the effects of the steam and the carbone dioxide atmospheres

At this stage of the study, one attempt to make comparison between the $\mathrm{CO}_{2}$ and the water steam used in our previous work [30]. For this purpose, we considered two gasification tests realized with $\left(20 \% \mathrm{H}_{2} \mathrm{O}\right.$, $\left.750{ }^{\circ} \mathrm{C}\right)$ in the previous study and $\left(40 \% \mathrm{CO}_{2}, 750{ }^{\circ} \mathrm{C}\right)$ in the present work and for the same sample EOMSW-OMWW. The ideal would be to compare exactly under the same conditions of temperature and gasifier percentage. However, even with a lower concentration the effect of $\mathrm{H}_{2} \mathrm{O}$ was stronger as it is shown below. The conversion levels versus time are shown in Fig. 11. The figure shows that the $\mathrm{CO}_{2}$ gasification exhibits a notable increase of the required time for $\mathrm{X}=0.9$ by nearly two times.

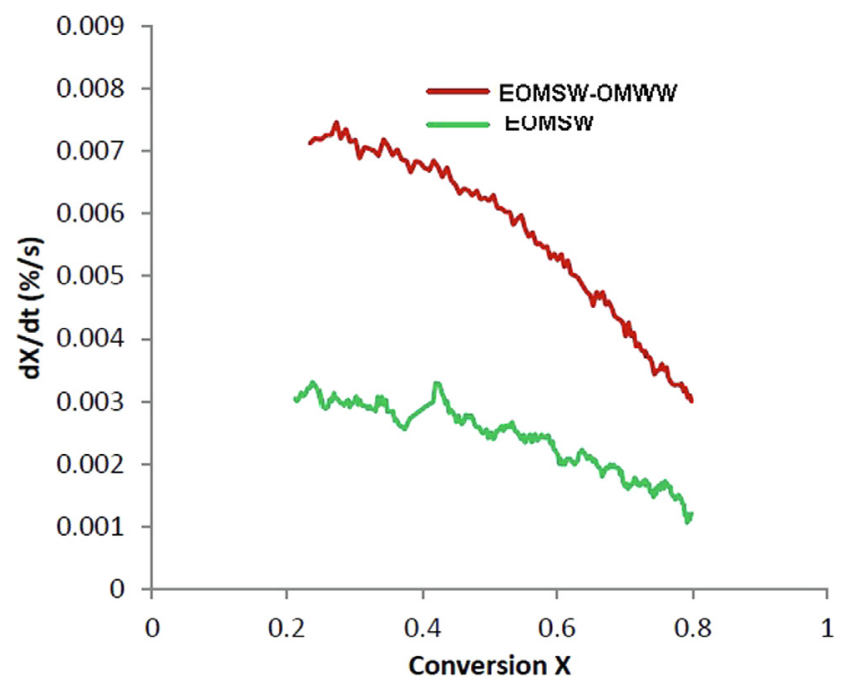

Fig. 9. Influence of the impregnation process on the rate of conversion of EOMSW under $70 \% \mathrm{CO}_{2}$ and at $800{ }^{\circ} \mathrm{C}$.

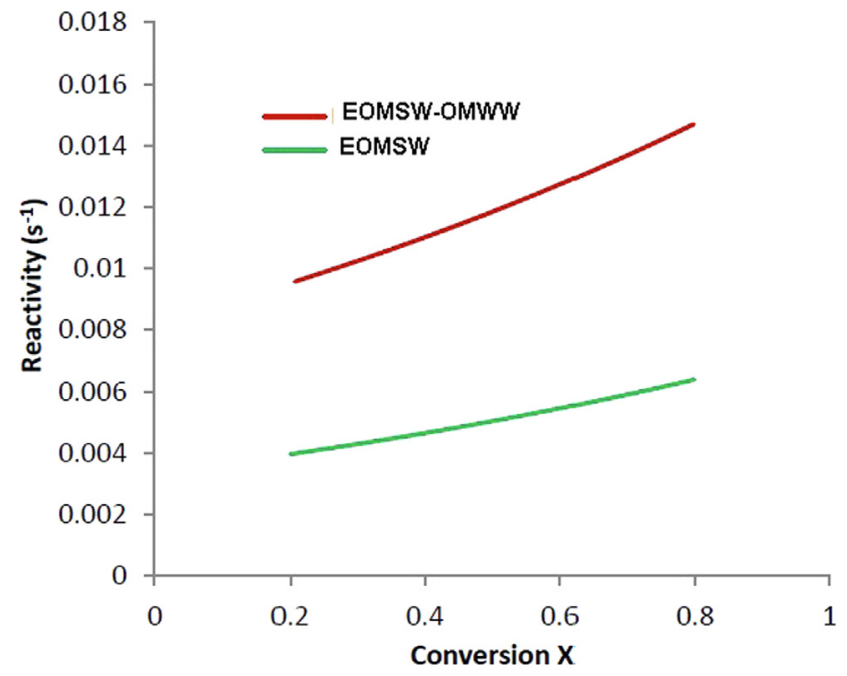

Fig. 10. Influence of the impregnation process on the char gasification reactivity of EOMSW under $70 \% \mathrm{CO}_{2}$ and at $800{ }^{\circ} \mathrm{C}$.

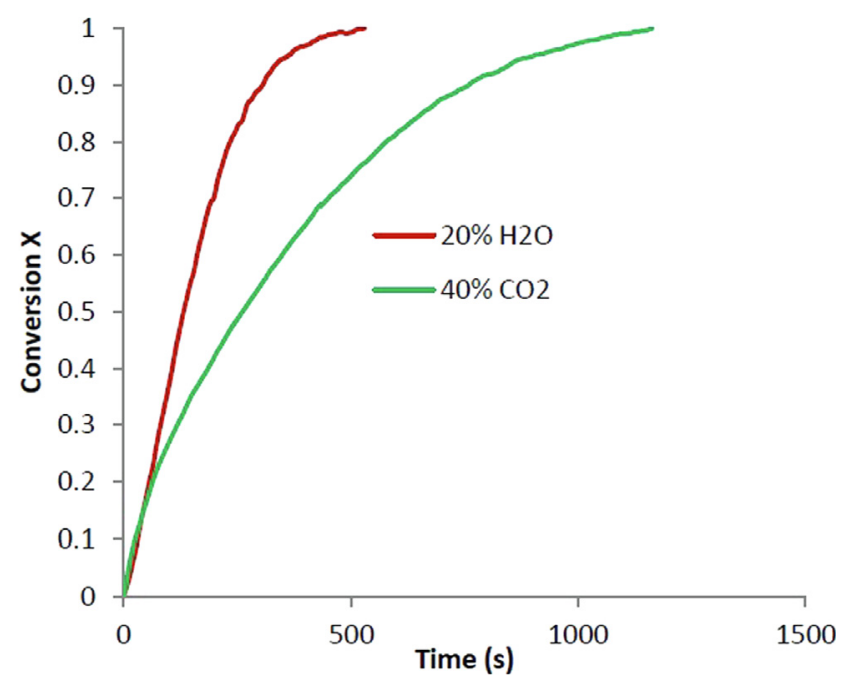

Fig. 11. Influence of the gasifier agent on the conversion of the impregnated EOMSW at $750{ }^{\circ} \mathrm{C}$.

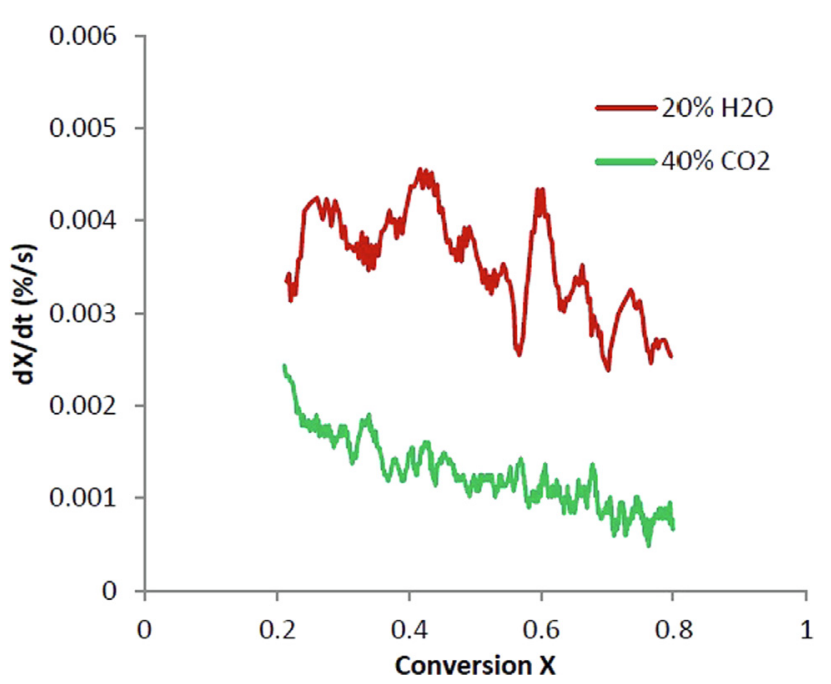

Fig. 12. Influence of the gasifier agent on the rate of conversion of the EOMSW at $750{ }^{\circ} \mathrm{C}$. 


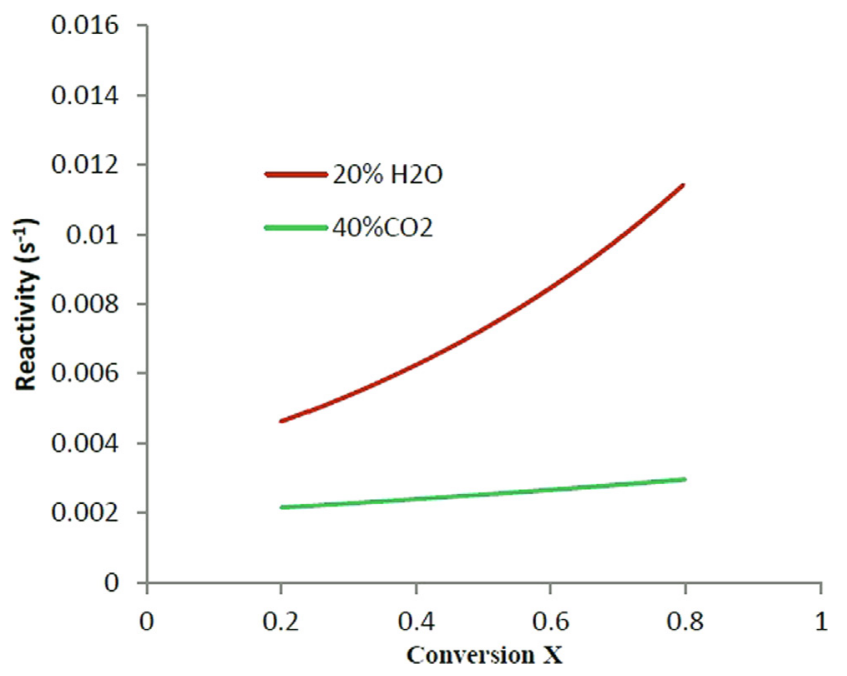

Fig. 13. Influence of the gasifier agent on the char gasification reactivity of the EOMSW at $750{ }^{\circ} \mathrm{C}$.

This behavior are consistent with the results reported by [35,39,47] who proved that at the same temperature, the gasification is enhanced by replacing $\mathrm{CO}_{2}$ with $\mathrm{H}_{2} \mathrm{O}$.

Figs. 12 and 13, showing the rates of conversion and the reactivity, confirm the same trend with the rate of $\mathrm{CO}_{2}$ gasification being slower than the rate of the steam gasification. Again, this result is consistent with results reported in the literature $[48,49]$ showing that gasification with $\mathrm{H}_{2} \mathrm{O}$ is two to five times faster than with $\mathrm{CO}_{2}[35,50]$. This gap is may be due to the difference in the intrinsic reactivity of $\mathrm{C}-\mathrm{H}_{2} \mathrm{O}$ and C$\mathrm{CO}_{2}$ reactions [35]. Thus, Tong et al. [39] have proved that at the same temperature, and with three different atmospheres, the gasification rate was higher with: $50 \% \mathrm{~N}_{2} / 50 \% \mathrm{H}_{2} \mathrm{O}, 50 \% \mathrm{CO}_{2} / 50 \% \mathrm{H}_{2} \mathrm{O}$ and $50 \% \mathrm{~N}_{2}$ / $50 \% \mathrm{CO}_{2}$ respectively, while the order of peak reaction rates was $50 \% \mathrm{CO}_{2} / 50 \% \mathrm{H}_{2} \mathrm{O}, 50 \% \mathrm{~N}_{2} / 50 \% \mathrm{H}_{2} \mathrm{O}$ and $50 \% \mathrm{~N}_{2} / 50 \% \mathrm{CO}_{2}$ respectively. Also, they concluded that the average reaction rate in $50 \% \mathrm{CO}_{2} / 50 \%$ $\mathrm{H}_{2} \mathrm{O}$ atmosphere was slower than $50 \% \mathrm{~N}_{2} / 50 \% \mathrm{H}_{2} \mathrm{O}$ which indicates that $\mathrm{CO}_{2}$ and $\mathrm{H}_{2} \mathrm{O}$ compete for the same reaction active pores on the char surface area. Moreover, when increasing the temperature, the competition power of $\mathrm{CO}_{2}$ over $\mathrm{H}_{2} \mathrm{O}$ increases gradually, so that $\mathrm{CO}_{2}$ was able to occupy more active sites (pores) than $\mathrm{H}_{2} \mathrm{O}$ when the temperature reaches $1433^{\circ} \mathrm{C}$.

\subsection{Determination of the reactivity profile $F(X)$}

Next, we investigate the reactivity profile, $F(X)$. Fig. 14 shows this reactivity profile as a function of conversion level, $\mathrm{X}$. The average reactivity profiles for $\mathrm{H}_{2} \mathrm{O}$ and $\mathrm{CO}_{2}$ show practically the same trends, except that for the $\mathrm{H}_{2} \mathrm{O}$ the reactivity profile exhibits a steeper and more nonlinear trend in terms of X. This may be due, according to [28], to the limited access of the $\mathrm{CO}_{2}$ molecules to the core of the char particle, despite the advanced gasification stage. The average of the function obtained for the $\mathrm{H}_{2} \mathrm{O}$ gasification experiments has the following expression:

$F^{H 2 O}(x)=1.0223 X^{2}+0.4893 X+0.7379$

While the structural function corresponding to $\mathrm{CO}_{2}$ gasification can be expressed as:

$F^{C O 2}(x)=0.6672 X^{2}+0.14 X+0.8646$

\subsection{Synthetic summary on discussions}

Following the discussions widely undertaken above, the following points can be noticed:

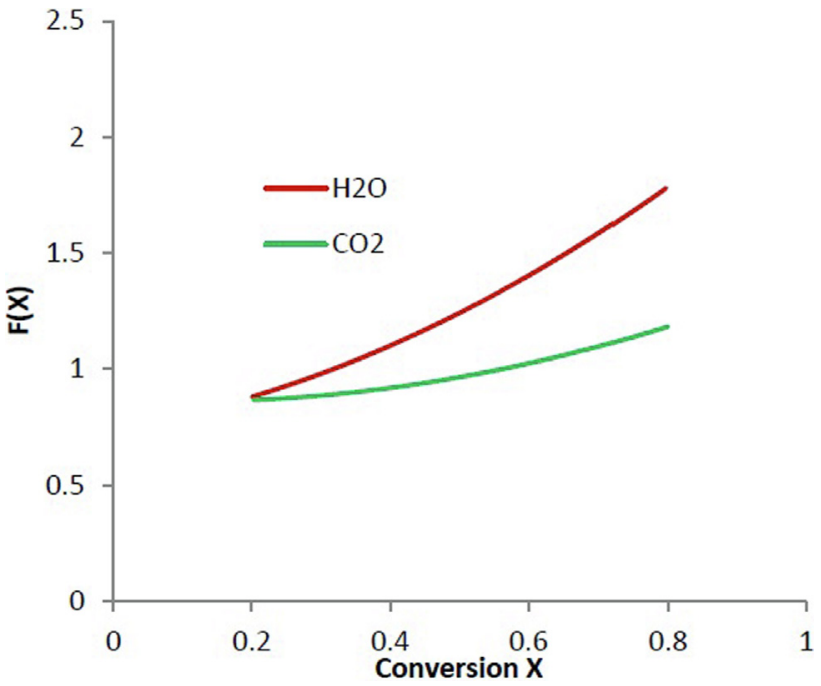

Fig. 14. Evolution of structural function versus conversion using steam and carbon dioxide.

- The 4 samples prepared from impregnated and non-impregnated blends of EOMSW and PS using OMWW as impregnation agent show different behaviour compared to woody biomass during gasification. Indeed, we found that there is no $\mathrm{CO}_{2}$ percentage effect limitation as it was stated by Guizani et al. [28] for whom $30 \% \mathrm{CO}_{2}$ is the limit for maximum reactivity. This is may be attributed to the specificity of samples used in this study (mainly organic and inorganic composition) per rapport to wood chips used by Guizani et al. [28].

- Despite that the kinetic model and experiment exhibit the same trend; we do not observe a perfect agreement between results of the experiment and of the model. This may be attributed to the fact that the chosen model by Hognon et al. [33] was simple and not very suitable to the studied sample type. This result will provide some guidance to improve the model by considering the samples' inorganic composition (mainly $\mathrm{K}, \mathrm{Si}, \mathrm{P}$ ) playing a crucial role in the kinetics of gasification due to their catalytic effects.

- The impregnation process using OMWW enriches the samples by inorganic elements which enhance the char reactivity and reduce the characteristic time for a $90 \%$ of conversion by more than a factor of 3.

- It was clear that $\mathrm{H}_{2} \mathrm{O}$ effect is stronger than $\mathrm{CO}_{2}$. Moreover, $\mathrm{CO}_{2}$ and $\mathrm{H}_{2} \mathrm{O}$ compete for the same reaction active pores on the char surface area. Furthermore, when increasing the temperature, the competition power of $\mathrm{CO}_{2}$ over $\mathrm{H}_{2} \mathrm{O}$ increases gradually, so that $\mathrm{CO}_{2}$ was able to occupy more active sites (pores) than $\mathrm{H}_{2} \mathrm{O}$ when the temperature reaches high levels.

\section{Conclusion}

The objective of this work was to carry out gasification experiments on four different chars provided from Tunisian and French biomasses (OMSW, OMWW and PS) under different isothermal temperatures and different percentages of carbon dioxide mixed with nitrogen $\left(\mathrm{N}_{2}\right)$. It is shown that the conversion, the rate of conversion and the char's reactivity increase with temperature for a given carbon dioxide percentage and vice versa. Moreover, the EOMSW-OMWW exhibits the highest gasification rate due to the richness of the samples in inorganic elements $(\mathrm{K}, \mathrm{Na}, \mathrm{Ca}$ ) concentrated especially in the OMWW. Furthermore, the gasification using the steam was found to be more reactive than the gasification via the carbon dioxide due to the difference in the intrinsic reactivity of $\mathrm{C}-\mathrm{H}_{2} \mathrm{O}$ and $\mathrm{C}-\mathrm{CO}_{2}$ reactions. Finally, the simple model used for describing the gasification kinetic was not adequate for the used samples. Hence, an improvement of the model based on inorganic 
compounds known by their catalytic effects should be investigated in our future work.

\section{CRediT authorship contribution statement}

M. Zribi: Validation, Formal analysis, Writing - original draft. M. Lajili: Conceptualization, Methodology, Formal analysis, Investigation, Writing - review \& editing, Visualization, Supervision, Project administration. F.J. Escudero-Sanz: Methodology, Formal analysis, Writing review \& editing.

\section{Declaration of Competing Interest}

The authors declare that they have no known competing financial interests or personal relationships that could have appeared to influence the work reported in this paper.

\section{Acknowledgements}

Marwa Zribi would like to express her sincere gratitude to Professor Ange Nzihou the director of Mines Albi and to Professor Sylvain Salvador for receiving her in the RAPSODEE laboratory.

\section{References}

[1] Bapat DW, Kulkarni SV, Bhandarkar VP. Design and operating experience on fluidized bed boiler burning biomass fuels with high alkali ash. Vancouver, New York, NY: ASME; 1997. p. 165-74.

[2] Saidur R, Abdelaziz EA, Demirbas A, Hossain MS, Mekhilef S. A review on biomass as a fuel for boilers. Renew Sustain Energy Rev 2012;15:2262-89.

[3] Heidenreich S, Foscolo PU. New concepts in biomass gasification. Prog Energy Combust Sci 2015;46:72-95.

[4] Felicimo AM, Gomez A, Munoz J. Potential distribution of forest species in dehesas of Extremadura (Spain). Adv Geoecol 2004;37:231-46.

[5] Verma VK, Barm S, Delattin F, Laha P, Vandendeal I, Hubin A, et al. Agropellets for domestic heating boilers: standard laboratory and real life performance. Appl Energy 2012;90:17-23.

[6] Sebban A, Bahloul A, Saadoune M, Kassi AA, Berrada M, Pineau JL, et al. Schéma de valorisation des grignons d'Olives produits les Maasras Marocaines (in French). Déchets-Revue Francophone d'Ecologie Industrielle 2004;34:39-43.

[7] Tsagaraki E, Lazarides HN, Petrotos KB. Olive mill wastewater. In: Oreopoulou V, Russ W, editors. Utilisation of by-products and treatment of waste in the food industry. Springer, Boston: MA; 2007. p. 133-57.

[8] Boari G, Brunetti A, Passino R, Rozzi A. Anaerobic digestion of olive oil mill wastewater. Agriculture Wastes 1984;10:161-75.

[9] Caputo AC, Scacchia F, Pelagagge PM. Disposal of by-products in olive oil industry: waste to energy solutions. App Therm Eng 2003;23:197-214.

[10] Balice V, Boari G, Cera O, Abbaticchio P. Indagine analittica sulle acque di vegetazione, Nota 1. Inquinamento 1982;7:49-53.

[11] Jeguirim M, Chouchene A, Reguillon AF, Trouvé G, Le Buzit G. A new valorisation strategy of olive mill waste water: Impregnation on sawdust and combustion. Resour Conserv Recycl 2012;59:4-8.

[12] Kraeim N, Jeguirim M, Limousy L, Lajili M, Dorge S, Michelin L, et al. Impregnation of olive mill wastewater on dry biomasses: Impact on chemical properties and combustion performances. Energy 2014;78:479-89.

[13] Jeguirim M, Dutourmié P, Zopras A, Limousy L. Olive Mill Wastewater: From a pollutant to Green Fuels, Agricultural Water Source and Bio-Fertilizer-Part 1. The drying kinetics. Energies 2017;10:1-16.

[14] McKendry P. Energy production from biomass (part 2): Conversion technologies. Bioresour Technol 2002;83:47-54.

[15] Jahirul MI, Rasul MG, Chowdhury AA, Ashwath N. Biofuels Production through Biomass Pyrolysis-A Technological Review. Energies 2012;5:4952-5001.

[16] Gagliano A, Nocera F, Bruno M, Blanco I. Effectiveness of thermodynamic adaptive equilibrium models for modeling the pyrolysis process. Sustainable Energy Technol Assess 2018;27:74-82.

[17] Kohse-Höinghaus OP, Cool TA, Kasper T, Hansen N, Qi F, Westbrook CK, et al Angew Chem Int Ed 2010;49:3572-97.

[18] Mami MA, Mätzing H, Gehrmann H-J, Stapf D, Bolduan R, Lajili M. Investigation of the Olive Mill Solid Wastes Pellets Combustion in a Counter-Current Fixed Bed Reactor. Energies 2018;11:1-21.

[19] Sikarwar VS, Zhao M, Fennell PS, Shah N, Anthony EJ. Progress in biofuel production from gasification. Prog Energy Combust Sci 2017;61:189-248.

[20] Farzad S, Mandegari MA, Görgens JF. A Critical review on biomass gasification, cogasification, and their environmental assessments. Biofuel Res J 2016;12:483-95.

[21] Wu H, Liu Q, Bai Z, Xie G, Zheng J, Su B. Thermodynamics analysis of a novel steam/air biomass gasification combined cooling, heating and power system with solar energy. App Therm Eng 2020;164:114494.

[22] Umeki K, Yamamoto K, Yochikawa T. High temperature steam-only gasification of woody biomass. Appl Energy 2010;87:791-8.

[23] Zhou J, Chen Q, Zhao H, Cao X, Mei Q, Luo Z, et al. Biomass-Oxygen gasification in a high-temperature entrained-flow gasifier. Biotechnol Adv 2009;27:606-11.

[24] Qin K, Lin W, Jensen PA, Jensen AD. High-temperature entrained flow gasification of biomass. Fuel 2012;93:589-600.

[25] Di Blasi C. Combustion and gasification rates of cellulosic chars. Prog Energy Combust Sci 2009;35:121-40.

[26] Manatura K, Lu JH, Wu KT, Hsu HT. Exergy analysis on torrefied rice husk pellet in Fluidized Bed gasification. App Therm Eng 2017;111:1016-24.

[27] Ostrowski P, Maj I, Kalisz S, Polok M. Biomass low-temperature gasification in a rotary reactor prior to cofiring of syngas in power boilers. App Therm Eng 2017;118:785-95.

[28] Guizani C, Escudero Sanz FJ, Salvador S. The gasification reactivity of high-heatingrate chars in single and mixed atmospheres of $\mathrm{H} 2 \mathrm{O}$ and $\mathrm{CO} 2$. Fuel 2013;108:812-23.

[29] Zribi M, Lajili M, Escudero Sanz FJ. Hydrogen enriched syngas production via gasification of biofuels pellets/powders blended from olive mill solid wastes and pine sawdust under different water steam/nitrogen atmospheres. Int J Hydrogen Energy 2019;44:11280-8.

[30] Sikarwar VS, Zhao M, Clough P, Yao J, Zhong X, Memon MZ, et al. An overview of advances in biomass gasification. Energy Environ Sci 2016;9:2927-3304.

[31] Li CZ. Importance of volatile-char interactions during the pyrolysis and gasification of low-rank fuels - A review. Fuel 2013;112:609-23.

[32] Lajili M, Guizani C, Escudero-Sanz FJ, Jeguirim M. Fast pyrolysis and steam gasification of pellets prepared from olive oil mill residues. Energy 2018;150:61-8.

[33] Hognon C, Dupont C, Grateau M, Delrue F. Comparison of steam gasification reactivity of algal and lignocellulosic biomass: Influence of inorganic elements. Bioresour Technol 2014;164:347-53.

[34] Ollero P, Serrera A, Arjona R, Alcantarilla S. The $\mathrm{CO}_{2}$ gasification kinetics of olive residue. Biomass Bioenerg 2003;24:151-61.

[35] Van de steene V, Tagutchou JP, Escudero Sanz FJ, Salvador S. Gasificationof wood particles: Experimental and numerical study of char-H2O, char-CO2, and char-O2 reactions. Chem. Eng. Sci. 2011; 66:4499-4509.

[36] Molina A, Mondragón F. Reactivity of coal gasification with steam and CO2. Fuel 1998;77(15):1831-9. https://doi.org/10.1016/S0016-2361(98)00123-9.

[37] Dsappa S, Pail PJ, Mukunda HS, Shrinivasa U. The gasification of wood-char spheres in CO2-N2 mixtures: analysis and experiments. Chem Eng Sci 1994;49:223-32.

[38] Yao X, Yu Q, Wang K, Xie H, Qin Q. Kinetic characterisation of biomass char CO2 gasification reaction within granulated blast furnace slag. Int J Hydrogen Energy 2017;42:20520-8.

[39] Tong S, Li L, Duan L, Zaho C, Anthony EJ. A kinetic study on lignite char gasification with $\mathrm{CO} 2$ and $\mathrm{H} 2 \mathrm{O}$ in a fluized bed reactor. Appl Therm Eng 2019;147:602-9.

[40] Mani T, Mahinpey N, Murugan P. Reaction kinetics and mass transfer studies of biomass char gasification with CO2. Chem Eng Sci 2011;66:36-41.

[41] Hodge EM, Roberts DG, Harris DJ, Stubington JF. The significance of char morphology to the analysis of high-temperature char- $\mathrm{CO} 2$ reaction rates. Energy Fuel 2009;24:100-7.

[42] Baláš M, Lisý M, Štelcl O. The effect of Temperature on the Gasification Process. Acta Polytechnica 2012;52:7-11.

[43] Baláš M, Lisý M, Pospíšil J. Steam Biomass Gasification-Effect of Temperature. Mech Mater 2016;832:49-54.

[44] Jeguirim M, Kraiem N, Lajili M, Guizani C. The relationship between mineral contents, particle matter and bottom ash distribution during pellet combustion: molar balance and chemometric analysis. Environ Sci Pollut Res 2017;24:9927-39.

[45] Li R, Zhang J, Wang G, Ning X, Wang X, Wang P. Study on CO2 gasification reactivity of biomass char derived from high-temperature rapid pyrolysis. App Therm Eng 2017;121:1022-31.

[46] Chouchene A, Jeguirim M, Trouvé G, Favre-Reguillon A, Le Buzit G. Combined process for the treatment of olive oil mill wastewater: Adsorption on sawdust and combustion of the impregnated sawdust. Bioresour Technol 2010;101:6973-82.

[47] Guizani C, Jeguirim M, Gadiou R, Escudero Sanz FJ, Salvador S. Biomass char gasification by $\mathrm{H} 2 \mathrm{O}, \mathrm{CO} 2$ and their mixture: Evolution of chemical, textural and structural properties of the chars. Energy 2016;112:133-45.

[48] Roberts DG, Harris DJ. Char Gasification with O2, CO2, and H2O: Effects of Pressure on Intrinsic Reaction Kinetics. Energy Fuel 2000;14:483-9.

[49] Wang P, Means N, Shekhawat D. Berry D The reactivity of coal char in chemical looping gasification and combustion, World of Coal Ash (WOCA) conference. Tennessee: Nasvhille; 2015.

[50] Harris DJ, Smith IW. Intrinsic reactivity of petroleum coke and brown coal to carbon dioxide, steam and oxygen. Proc Combust Inst 1990;23:1185-90. 